\title{
HIGH RESOLUTION X-RAY COMPUTED TOMOGRAPHY FOR PETROLOGICAL CHARACTERIZATION OF SPELEOTHEMS
}

\author{
Valentina Vanghi', , Eneko Iriarte', and Arantza Aranburu ${ }^{3}$
}

\begin{abstract}
High resolution X-ray computed tomography (HRXCT) has been barely used in speleothem science. This technique has been used to study a Holocene stalagmite from Praileaitz Cave (Northern Spain) to evaluate its potential for petrologic studies. Results were compared with those derived from the routine procedures and a very good correlation was found. Our work indicates that HRXCT can be considered as a useful tool for a rapid and non-destructive characterization of the speleothem, providing important information about petrological textures, spatial distribution of porosity, and diagenetic alteration, as well as stratigraphic architecture. These encouraging results indicate that HRXCT can offer interesting perspectives in speleothem science that are worth future exploration.
\end{abstract}

\section{INTRODUCTION}

Speleothem records are widely considered as reliable archives for multi-proxy based paleoclimatic reconstruction of continental regions. Geochemical and physical changes that may occur during the formation of speleothems are controlled by environmental conditions (Fairchild and Baker, 2012). This is why the study of the petrology of a speleothem is important, because crystals' morphology and their mechanisms of growth may provide useful information related to the physical and chemical characteristic of the drips (Sunagawa, 1987; Frisia et al., 2000). Speleothems are also affected by diagenetic processes such as dissolution, corrosion, micritization, and recrystallization. (Frisia and Borsato, 2010; Railsback et al., 2011). These processes may lead to the modification of their original geochemical signals, thus compromising the validity of the chronological results and the environmental interpretations that may be extracted. For example, percolating water may infiltrate the crystalline fabrics through dissolution paths or a network of interconnected pores, thus inducing diagenetic transformations (Frisia et al., 2000; Borsato et al., 2003). Consequently, it is crucial to study the spatial distribution of the primary porosity in order to identify the existence of internal heterogeneities that may lead to the formation of secondary porosity. These petrophysical properties are directly related to speleothem fabrics, microfabrics, and internal microstratigraphy (Muñoz-García et al., 2012). These features are studied through the petrological analysis of speleothems, which is commonly based on a combination of techniques like optical microscopy and scanning and transmission electron microscopy (Frisia and Borsato, 2010; Fairchild and Baker, 2012; Railsback, 2000).

High-resolution X-ray computed tomography (HRXCT) is a technique that allows non-destructive imaging and quantification of internal features of objects. Originally developed as a medical-imaging tool, over the last decades it has been increasingly used for the study of geomaterials in engineering and geosciences such as petrology, sedimentology, and paleontology (e.g., Mees et al., 2003). However, this technique has only rarely been applied to speleothems (Mickler et al., 2004), although it has great potential, being non-destructive, allowing rapid acquisition, and producing high-resolution data. In 2004, Mickler and colleagues published a research paper concerning the application of HRXCT in speleothem science. In this paper, the authors use X-ray computed tomography to identify the position of the growth axes of two stalagmites to ensure a correct longitudinal cut without causing damage that would compromise their applicability as geochemical climate proxies. Following these encouraging results, we use this technique to evaluate the potential of HRXCT for petrophysical characterization of a speleothem. This study presents an evaluation of the spatial distribution and variation of the porosity and density values obtained by HRXCT on a stalagmite sample. Results were then compared with those derived from the standard procedure of optical and scanning electron microscopy.

\section{MATERIALS AND METHODS}

\section{SAMPLING}

The stalagmite, named Novella, was sampled at Praileaitz Cave in the Basque Country of northern Spain. Further information about this cave and its geological context may be found in Vanghi (2013a and b) and references therein. In the laboratory, the stalagmite was longitudinally cut in two halves with an electric saw

\footnotetext{
${ }^{1}$ Universidad de Burgos, Departamento Ciencias Históricas y Geografía Plaza de Misael Bañuelos s/n, 09001, Burgos, Spain, eiriarte@ubu.es

${ }^{2}$ Current: University of Newcastle, School of Environmental and Life Sciences, Faculty of Science and Information Technology, University drive, Callaghan 2308 NSW, Australia, valentina.vanghi@uon.edu.au

${ }^{3}$ Universidad del País Vasco, Dpto. de Mineralogía y Petrología, Facultad de Ciencia y Tecnología, Ap. 644-48080, Bilbao, Spain, arantza.aranburu@ehu.es
} 


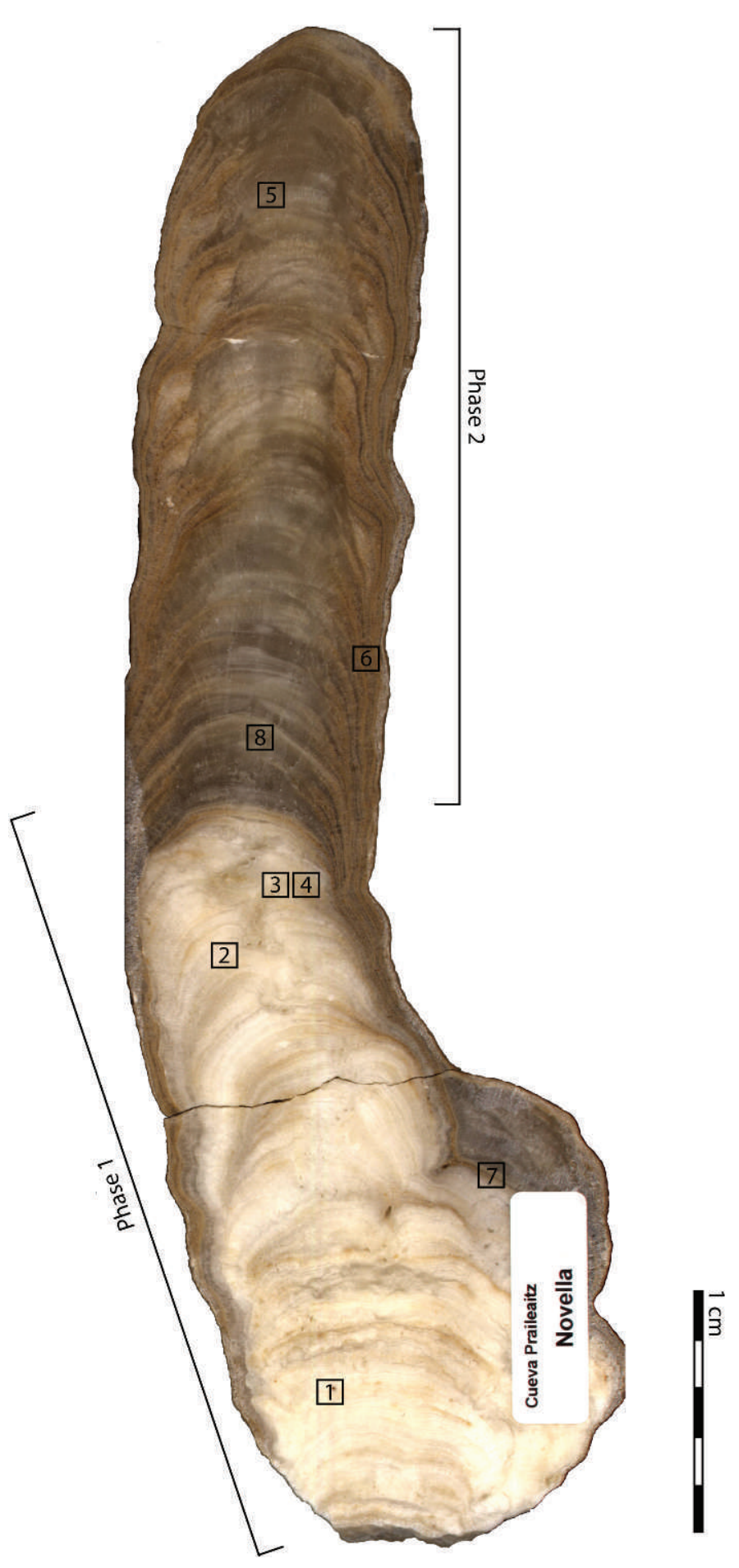

Figure 1. Longitudinal section of the stalagmite Novella. The two stratigraphic phases are also indicated. The numbered boxes correspond to the locations of the photographs showed in Figure 2.

(Fig. 1). The stalagmite is approximately 35-cm long and varies in width from $9.5 \mathrm{~cm}$ at the base to $6 \mathrm{~cm}$ at the top. Additionally to HRXCT and petrology studies, Novella's stable isotopes and trace elements were also studied (Vanghi, $2013 \mathrm{a}$ and b). This speleothem record is chronologically constrained by U-Th ages from two samples collected at the bottom of Phase 1 in its growth $(10.7 \pm 0.09 \mathrm{ka} \mathrm{BP})$ and at the transition between Phases 1 and $2(6.77 \pm 0.07 \mathrm{ka} \mathrm{BP})$ obtained by multi-collector inductively-coupled plasma mass-spectroscopy.

\section{Petrology}

A petrologic study was carried out for the characterization and description of the different fabrics, as well as for the identification of all the diagenetic features present in the stalagmite. To do so, we made fourteen thin sections along the vertical growth axis of one entire fourth portion of the stalagmite. The areas chosen for each thin section were correlated between each other and overlapped in order to not lose information.

All the optical analyses were completed in the Laboratory of Human Evolution of the University of Burgos, Spain, using a Nikon Eclipse LV100POL optical microscope and the Nikon AZ100 binocular microscope coupled with the Nikon DS-FI1 digital camera. We got scanning electron microscope images using a GEOL JSM6460LV microscope.

\section{High-Resolution X-Ray Computed Tomography}

The basic components of X-ray computed-tomography scanners are an X-ray source, a detector, and a samplerotation system. CT images are created by directing a planar fan beam towards an object from multiple angles around a central axis, producing a sinogram. This step is followed by the reconstruction of a succession of twodimensional radiographs that correspond to what would be observed if the object was cut open along the image planes $y-x, x-z$, and $y-z$. The gray-scales in these images correspond to relative $\mathrm{X}$-ray attenuation, which is a function of elemental composition and density; and therefore, they reflect the physical properties of the object (Mickler et al., 2004). In other words, gray-values in the images correspond to the density values, expressed in Hounsfield units (HU), measured by the scan.

The analyses were performed at the University of Burgos, using an industrial scanner Xylon CT Compact. Xray energy and current were set to $225 \mathrm{kV}$ and $2.8 \mathrm{~mA}$, with a small focal spot. Only one half of the stalagmite was scanned by CT as the sample was previously sliced to perform the petrographic study. A total of 1780 slices were obtained, one slice every $0.2 \mathrm{~mm}$, generating images with a pixel size of $0.69 \mathrm{~mm}$. The data were processed using Materialise's Interactive Medical Image Control System (MIMICS) v.10 for reconstructing virtual images of scanned objects in two or three dimensions.

\section{Results AND Discussion}

An initial visual observation of the longitudinal section of the stalagmite led to the identification of two different phases of growth characterized by two different colorations 
(Fig. 1). Phase 1 is about $17 \mathrm{~cm}$ long from the base of the stalagmite, and has a whitish color and a porous aspect, whereas Phase 2 is about $18-\mathrm{cm}$ long and has a darker color, with compact and glassy aspect. The transition from Phase 1 to Phase 2 suggests some changes in the drip point, with a modification of the orientation of the growth axis of the stalagmite. X-ray diffraction analyses showed that the speleothem is entirely composed of calcite (Vanghi, 2013a).

\section{Petrology}

Petrological analyses allowed us to identify three different types of crystalline fabrics along the speleothem. Different crystalline fabrics dominate the two visible phases that show distinct colorations.

Phase 1 is dominated by the dendritic crystalline fabric, formed by interweaving thin and elongated crystals whose spatial distribution forms a net (Frisia, 2003; Fairchild et al., 2007) (Figs. 2.1 to 2.4). This texture is characterized by high intercrystalline porosity and thus by low density. The dimensions of the crystals vary, with widths between 25 and $50 \mu \mathrm{m}$ and lengths between 200 and $550 \mu \mathrm{m}$. These dimensions are significantly larger than those from the dendritic texture defined by Frisia and Borsato (2010). Those authors describe this fabric as formed by crystals a few $\mathrm{mm}$ long and between 4 and $10 \mu \mathrm{m}$ width; but nevertheless, we interpret ours as analogous and with the same genetic implications. Thin, closed dendritic fabric layers are present intercalated between dendritic fabric layers (Figs. 2.1 to 2.4). Closed dendritic crystals have more equal dimensions of 50 to $200 \mu \mathrm{m}$ and form less porous laminae. Phase 1 shows an alternation of millimeter-scale white and dark layers that reflect the intercalation between the above mentioned closed dendritic (white) and properly dendritic (black) fabrics (Fig. 2.1). This variation in the crystalline fabric forms an alternating distribution of the porosity values that is also recognizable in the CT-scan data.

Phase 2 is entirely formed of big columnar crystals. Columnar fabric is characterized by large crystals more than $100-\mu \mathrm{m}$ long and 50 to $100 \mu \mathrm{m}$ in width, growing parallel to the central axis (Fig. 2.5 to Fig. 2.8). Their crystal boundaries are serrated, even if sometimes separated by voids filled by fluid inclusions (Frisia and Borsato, 2010). In general, the columnar fabric is less porous than the dendritic fabric. Along the central axis of the stalagmite, these crystals grow perpendicular to the surface. Close to the flank of the stalagmite, columnar crystals become smaller, and their growth orientation becomes oblique to the surface. Some micritic layers are observed in Phase 2, mainly on the edges of the speleothem, but they do not reach the central axis of the stalagmite.

\section{Computed Tomography Scans}

MIMICS v.10 software was used to create different colored masks (Fig. 3), each one corresponding to distinct intervals of density values and reflecting the internal variability of the porosity in the stalagmite. These data may be then compared to the results derived from the petrologic analysis.

\section{Density Values vs. Fabrics}

The results derived from the X-ray CT scans combined with the petrologic study highlight the strong correlation between density values and crystalline fabrics. Different density value intervals, represented by different colors, reflect different observed crystalline textures, allowing for the recognition and reconstruction of the internal petrological architecture of the speleothem (see Figs. 3 and 4).

In addition, with the MIMICs v.10 program it is also possible to create $3 \mathrm{D}$ models of each density interval. Different tools in the software allow manipulation of the 3D model of the object, such as rotations, cuts, measurements, and opacity readings (Fig. 5). These could be important to better study the distribution and quantification of the different crystalline fabrics and porosity.

\section{Density Values vs. Stratigraphical Boundaries}

Differences in density values correspond to changes of crystalline fabrics, reflecting different environmental conditions of formation. In the studied speleothem, the CT scan helped to identify several stratigraphic subunits, especially within Phase 2, where macroscopic laminations can hardly be identified (Fig. 6). Therefore, CT scanning can also be a valid alternative or complement to ultraviolet light to discriminate the stratigraphic architecture of speleothems.

\section{Density Values vs. Distribution of the Porosity}

Studying the spatial distribution and characteristics of the porosity makes it possible to detect stratigraphic discontinuities, such as phases of no deposition, leading to alteration, micritization, or dissolution in the speleothem. This is especially important in speleothem science, because an accurate age model has to consider any existing hiatuses and because the presence of porosity may have allowed alteration of the primary isotopic and elemental composition of a speleothem, thus making it unsuitable for palaeoclimate studies (e.g., Mickler et al., 2004; Muñoz-García et al., 2012). In Novella most of the porosity, shown in Part E of Figure 5, occurs along the dendritic texture, although sometimes it is also distributed along stratigraphic boundaries.

\section{OTHER INTERESTS}

Computed tomography is also a useful non-destructive tool for rapid determination of the stalagmite growth axis position, as well as its spatial variation, without any sample manipulation or preparation. Growth bands' thicknesses in stalagmites tend to decrease away from the growth axis, so off-axis samples are more subject to non-equilibrium fractionation effects. This is why it is important to cut a stalagmite into longitudinal sections intersecting the central axis (Mickler et al., 2004). In addition, CT scanning could potentially be useful to identify the presence of other 

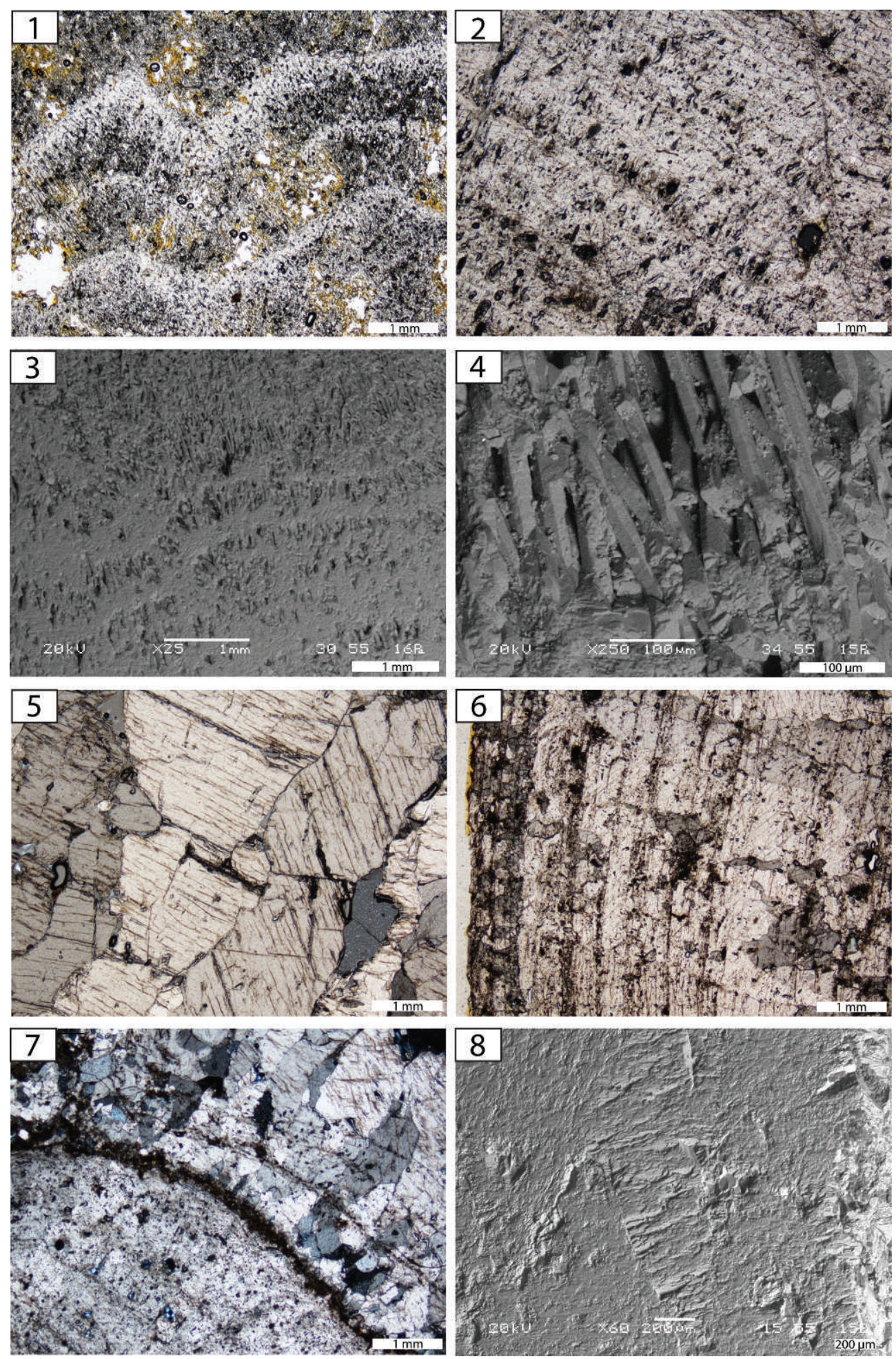

Figure 2. Thin-section photomicrographs under the petrographic microscope and the scanning electron microscope. Locations of the photographs are shown in Figure 1. (1) and (2) Alternation between dendritic and closed dendritic fabric in Phase 1. The white bands are formed by closed dendritic fabric, and the dark bands correspond to dendritic fabric. (3) Alternation of dendritic and mosaic fabrics under SEM. Notice the different porosity pattern in both fabrics. (4) Close up view of dendritic and mosaic crystals. (5) Columnar fabric in Phase 2. (6) Micritic layers interbedded in the columnar fabric close to the edge of the stalagmite. (7) Large dendritic crystals and small columnar crystals separated by a micritic layer, near the edge of the stalagmite. (8) SEM photograph of the columnar fabric in Phase 2. 


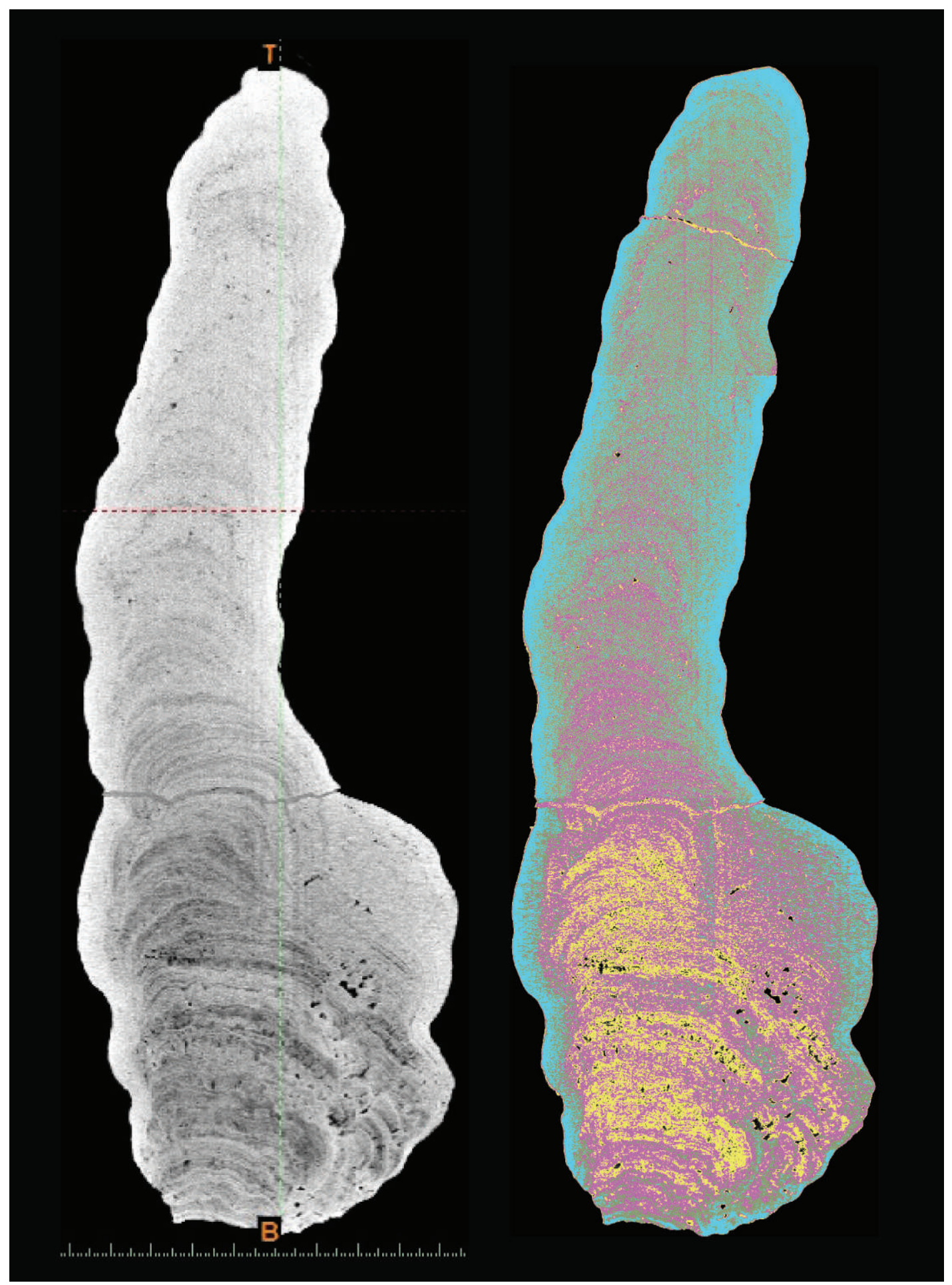

Figure 3. 2D image of section of the stalagmite Novella. On the left is the unprocessed radiograph of the stalagmite. On the right is the radiograph of the stalagmite with the different calculated density-ranges. Each color has been found to correspond to different crystalline textures recognized in the petrographic study. Black is -1024-226 Hounsfield units, lowest density values, air-filled porosity; yellow is $227-776 \mathrm{HU}$, low density values, dendritic crystalline texture; fuchsia is $777-1176 \mathrm{HU}$, medium density values, closed dendritic crystalline texture; green is $1177-1576 \mathrm{HU}$, high-density values, columnar crystalline texture; and blue is 1577-3071 $\mathbf{H U}$, highest density values, micritic crystalline texture. The colors are superimposed here, with those representing the lowest densities on top. 


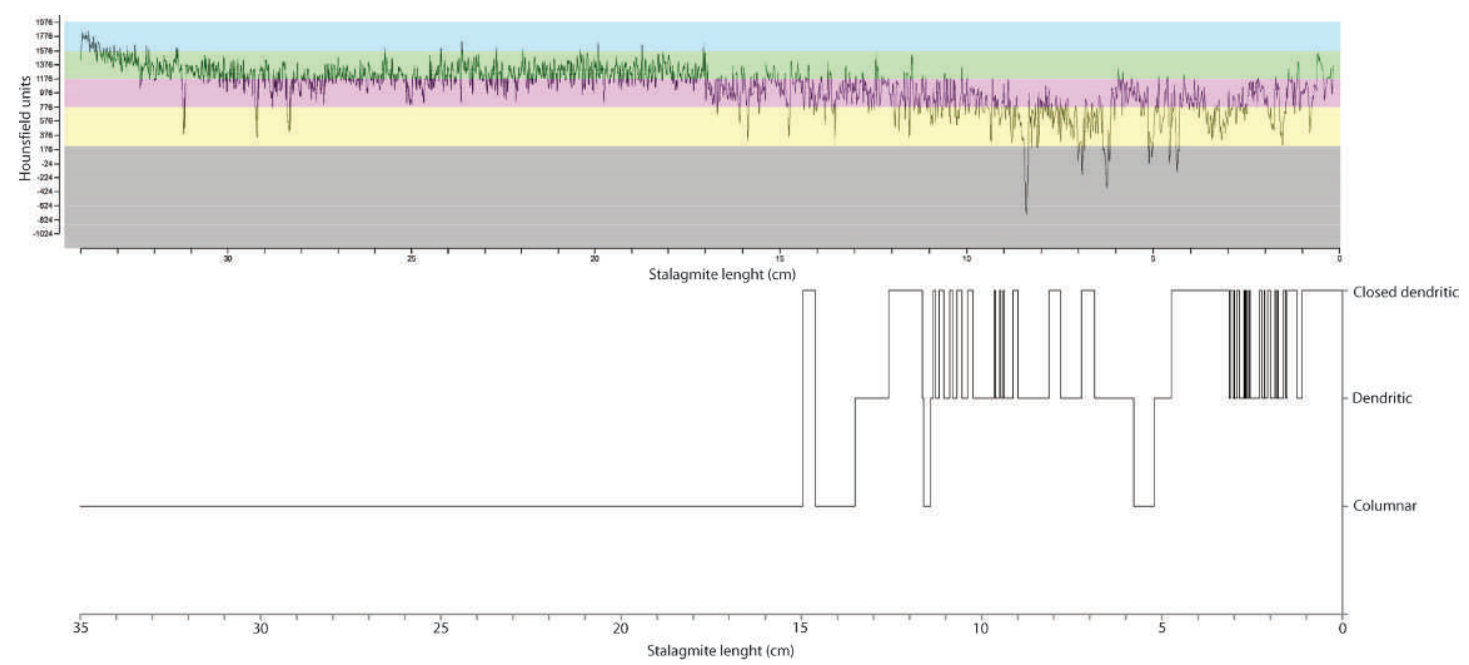

Figure 4. Petrographic log showing the different fabrics along the axis of the stalagmite compared with the graph of the density values in Hounsfield units, obtained with MIMICS v.10 software, that reflect the internal variability of the porosity in the speleothem. The color bands in the density graph correspond to the colors in Figures 3 and 5.

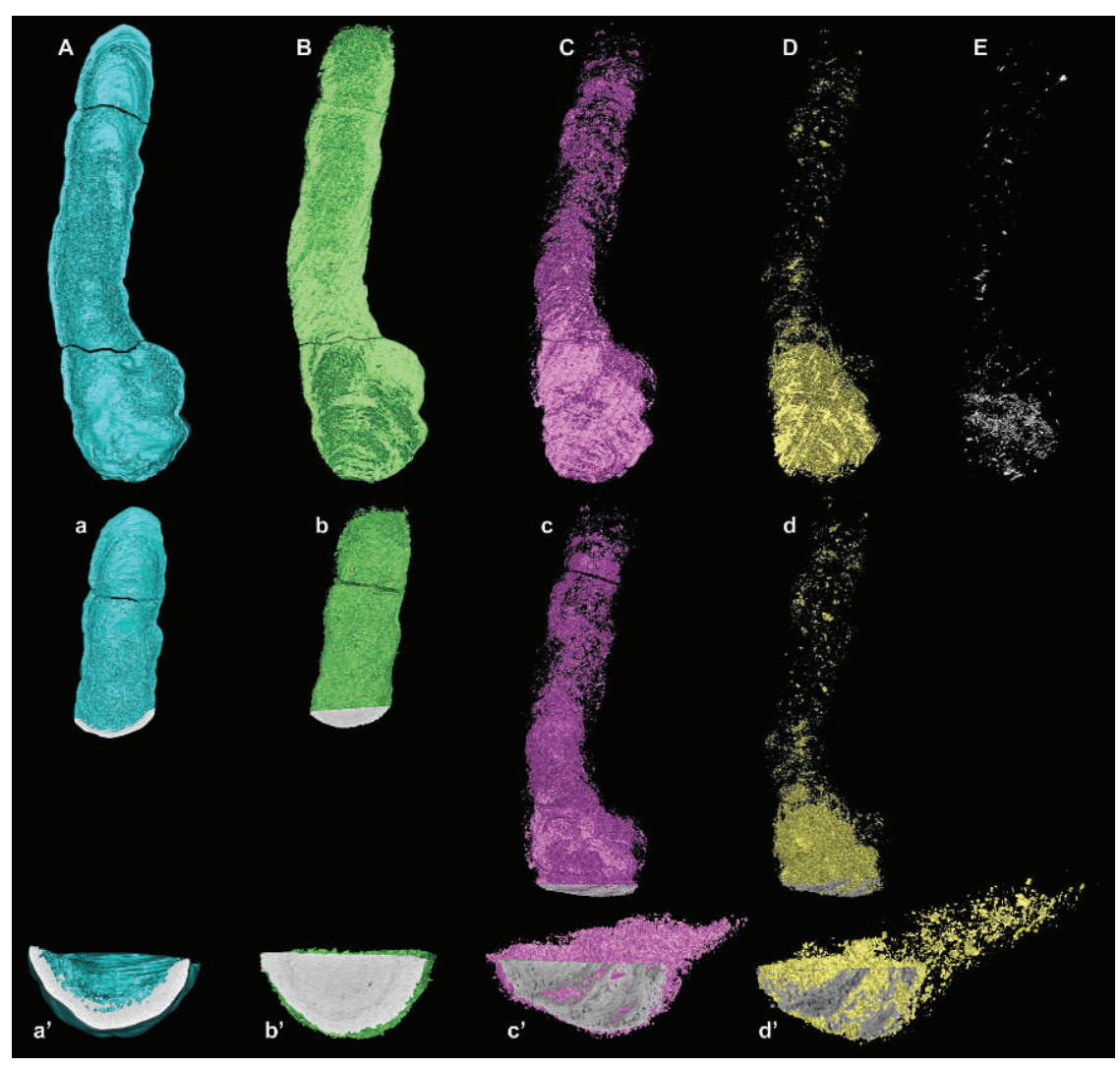

Figure 5. The top row is 3D models of the exterior of the stalagmite for different density value ranges according to MIMICS v.10. Density ranges corresponding to the inferred fabrics are listed in the caption for Figure 3. (A) Blue represents the lateral micrite-rich fabric; (B) green the columnar fabric; (C) fuchsia corresponds to closed dendritic fabric; (D) yellow correspond to the dendritic fabric; (E) stalagmite porosity distribution (density -1024 to $226 \mathrm{HU}$ ). The lower figures are the sections of each 3D image color that help to ascertain the fabric distributions. 

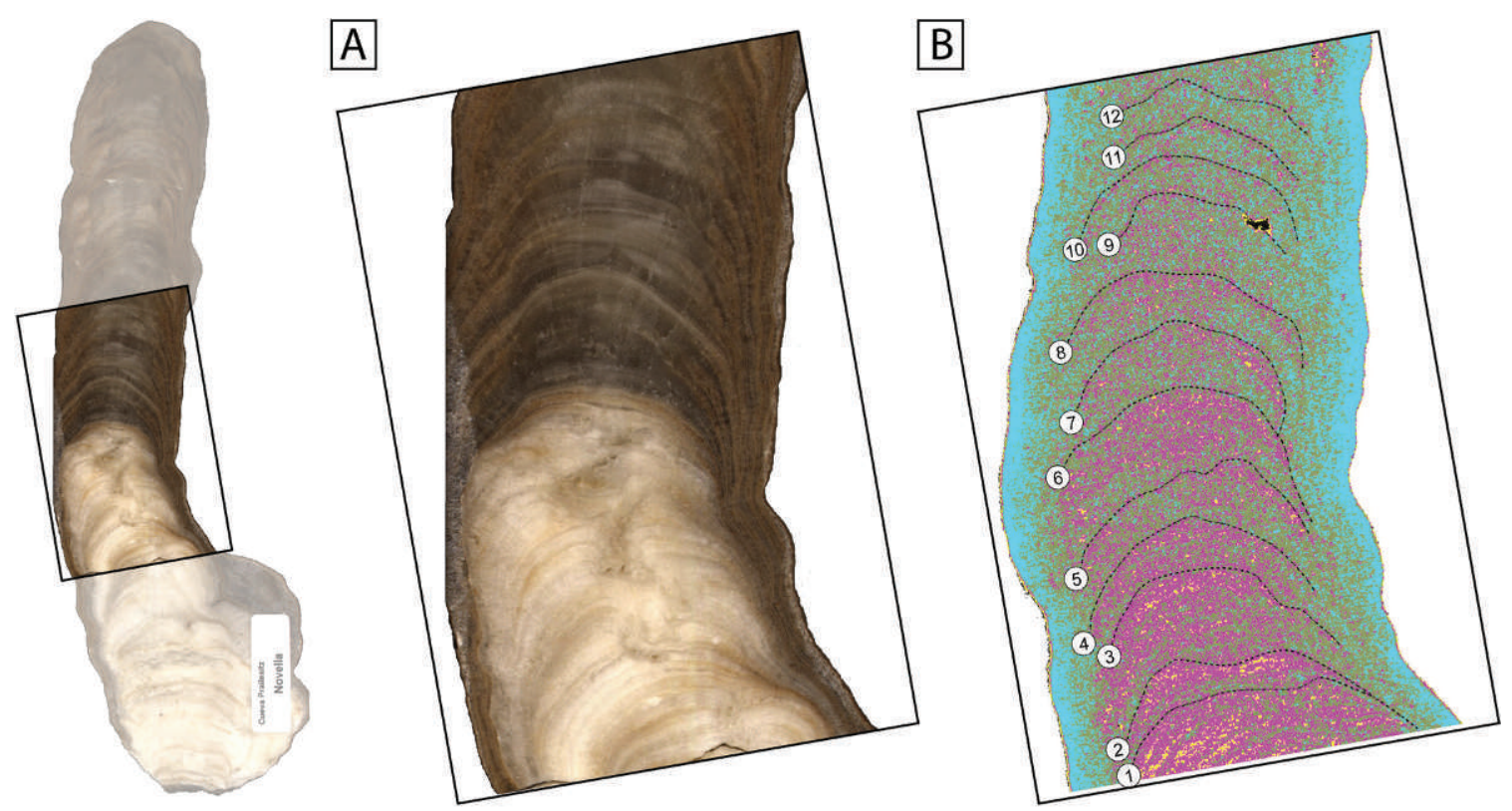

Figure 6. Enlargement of the images in Figures 1 and 3 of the phase-transition area in stalagmite Novella where stratigraphic architecture consisting of cyclic alternation of closed dendritic and columnar fabrics is visible. (A) is a photograph. (B) is the result of the computed-tomography scan, where fuscia color indicates closed dendritic fabric and green indicates columnar fabric. Compare the apparently sharp boundary between phases of the photograph and the gradual and cyclic pattern observed in the tomography. The annotations in (B) are explained in Vanghi (2013a).

interesting features, such as terrigenous, soot, charcoal, or guano laminae or masses inside the stalagmite.

\section{CONCLUSIONS}

In the present work, we evaluate the potential of computed-tomography scanning by comparing it with the results derived from a standard petrologic study. In that regard, our data indicate that CT scan has many interests for speleothem research. By definition, high-resolution Xray computed tomography may detect subtle variations of density. As density values in a speleothem are controlled by primary crystalline texture and the presence of secondary porosity due to dissolution or fractures, CT scans can be used as a tool for a rapid and non-destructive characterization of the speleothem petrological textures, porosity distribution, and stratigraphical architecture prior to any further analysis.

Porosity is related to fluid behavior in the different fabrics, and consequently, with the spatial distribution of the diagenetic processes such as dissolution or recrystallization and neomorphism. In that regard, CT scanning may help to determine whether the speleothem has remained as a geochemically closed system.

As in previous work (Mickler et al., 2004), our work indicates that high-resolution tomography shows an interesting potential for the study of speleothem record. This technique offers many interests, being non-destructive and producing high resolution data in a few hours. It is a reliable complement to the standard petrological analysis, as it may help identify the domains within a speleothem that are the most suitable for bulk geochemical analysis and dating. In that regard, it could be especially interesting to develop a more rapid CT scanning procedure in the future to evaluate the suitability of a speleothem before any further sample manipulation, preparation and analysis.

\section{ACKNOWLedGements}

We are grateful to Roberto Porres and Laura Rodríguez for their help and useful comments concerning the computed-tomography scan data-acquisition and processing. We would also like to thank Dr. Mathieu Duval for his helpful comments.

\section{REFERENCES}

Borsato, A., Quinif, Y., Bini, A., and Dublyansky, Y., 2003, Open-system alpine speleothems: Implications for U-series dating and paleoclimate reconstructions: Studi Trentini di Scienze Naturali, Acta Geologica, v. 80 , p. $71-83$.

Fairchild, I.J., Frisia, S., Borsato, A., Tooth, A.F., 2007, Speleothems, in Nasch, D.J., and Oxford, S.J., Geochemical Sediments and Landscapes: Oxford, Blackwells, p. 201-245.

Fairchild, I.J., and Baker, A., 2012, Speleothem Science: From Process to Past Environment: Chichester, UK, Wiley-Blackwell, Quarternary Geoscience Series, $432 \mathrm{p}$.

Frisia, S., Borsato, A., Fairchild, I.J., and McDermott, F., 2000, Calcite fabrics, growth mechanisms, and environments of formation in speleothems from the Italian Alps and southwestern Ireland: Journal 
of Sedimentary Research, v. 70, no. 5, p. 1183-1196. doi:10.1306/ 022900701183 .

Frisia, S., 2003, Le tessiture negli speleotemi: Studi Trentini di Scienze Naturali, Acta Geologica, v. 80, p. 85-94.

Frisia, S., and Borsato, A., 2010, Karst, in Alonso-Zarza, A.M., and Tanner, L.H., eds., Carbonates in Continental Settings: Facies, Environments and Processes: Amsterdam, Elsevier, Developments in Sedimentology, no. 61, p. 269-318.

Mees, F., Swennen, R., Van Geet, M., and Jacobs, P., 2003, Applications of X-ray computed tomography in geosciences, in Mees, F., Swennen, R., Van Geet, M., and Jacobs, P., eds., Applications of X-ray Computed Tomography in Geosciences: The Geological Society of London Special Publications, v. 215, p. 1-6. doi:10.1144/GSL.SP. 2003.215.01.01.

Mickler, P.J., Ketcham, R.A., Colbert, M.W., and Banner, J.L., 2004, Application of high-resolution X-ray computed tomography in determining the suitability of speleothems for use in paleoclimatic, paleohydrologic reconstructions: Journal of Cave and Karst Studies, v. 66, p. $4-8$.

Muñoz-García, M.B., López-Arce, P., Fernández-Valle, M.E., MartínChivelet, J., and Fort, R., 2012, Porosity and hydric behavior of typical calcite microfabrics in stalagmites: Sedimentary Geology, v. 265-266, p. 72-86. doi:10.1016/j.sedgeo.2012.03.016.
Railsback, L.B., 2000, An Atlas of Speleothem Microfabrics, prepared by the University of Georgia Laboratory for Speleothem Studies, http:// www.gly.uga.edu/railsback/speleoatlas/SAindex1.html [accessed November 2013].

Railsback, L.B., Liang, Fuyuan, Vidal Romaní, J.R., Grandal-d'Anglade, A., Vaqueiro Rodríguez, M., Santos Fidalgo, L., Fernández Mosquera, D., Cheng, Hai, and Edwards, R.L., 2011, Petrographic and isotopic evidence for Holocene long-term climate change and shorter-term environmental shifts from a stalagmite from the Serra do Courel of northwestern Spain, and implications for climatic history across Europe and the Mediterranean: Palaeogeography, Palaeoclimatology, Palaeoecology, v. 305, p. 172-184. doi:10.1016/j.palaeo. 2011.02.030.

Sunagawa, I., 1987, Morphology of minerals, in Sunagawa, I., ed., Morphology of Crystals, Part B: Tokyo, Terra Scientific Publishing Company, p. 509-587.

Vanghi, V., 2013a, Estudio multianalítico de una estalagmita, Novella (Cueva de Praileaitz, Gipuzkoa): detección y caracterización de indicadores de cambios ambientales: CKQ Quaternary Studies, v. 3, p. $135-159$.

Vanghi, V., 2013b, Trace element and isotopic study of a Holocene speleothem from Praileaitz Cave (Cantabrian Margin, Northern Spain): identifying proxies for paleoclimatological reconstruction [M.Sc. thesis]: University of Burgos, unedited. 